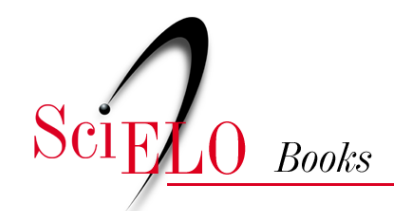

\title{
A cartografia da ação social e a cidade de São Gonçalo, RJ limites e possiblidades metodológicas para a contribuição do fazer geográfico
}

\author{
Catia Antonia da Silva
}

\section{SciELO Books / SciELO Livros / SciELO Libros}

SILVA, C.A. A cartografia da ação social e a cidade de São Gonçalo, RJ: limites e possiblidades metodológicas para a contribuição do fazer geográfico. In: MARAFON, G.J., and RIBEIRO, M.A. orgs. Revisitando o território fluminense, VI [online]. Rio de Janeiro: EDUERJ, 2017, pp. 353-366. ISBN: 978-85-7511-457-5. https://doi.org/10.7476/9788575114575.0018.

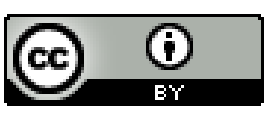

All the contents of this work, except where otherwise noted, is licensed under a Creative Commons Attribution 4.0 International license.

Todo o conteúdo deste trabalho, exceto quando houver ressalva, é publicado sob a licença Creative Commons Atribição 4.0.

Todo el contenido de esta obra, excepto donde se indique lo contrario, está bajo licencia de la licencia $\underline{\text { Creative Commons }}$ Reconocimento 4.0. 


\section{A cartografia da ação social e a cidade de São Gonçalo, RJ: limites e possiblidades metodológicas para a contribuição do fazer geográfico}

Catia Antonia da Silva ${ }^{l}$

\section{Introdução}

A cartografia da ação social é uma possibilidade metodológica que se inscreve na relação entre geografia e sociologia. Trata-se de reconhecer as trajetórias e as espacialidades escritas pelas práticas cotidianas das bases populares. Diante da aceleração do tempo-mundo, engendradas pela globalização e pelo desenvolvimentismo que o Brasil e a América Latina experimentam, os processos de modernização têm alterado profundamente a produção social do espaço feita pelos grandes agentes econômicos e o Estado. Produzir as cartografias dos homens e mulheres simples significa dar visibilidade e possibilidade de pensar sua própria condição, além de ter na cartografia um instrumento de representação de seu território e de luta social.

Nessa lógica, o objetivo deste trabalho é refletir sobre o sentido do uso da cartografia da ação social no contexto atual, demonstrando conceitos e metodologias utilizados que norteiam a compreensão da cartografia da ação social como um processo que se inicia na pesquisa e nos estágios de vivência com os jovens de São Gonçalo, mas não termina com a confecção de mapas. Ele é concluído quando o grupo social se apropria e, então, analisa as formas fundamentais do uso da cartografia como instrumento formador de sujeitos de direitos e de possiblidade de construção coletiva do olhar, da identidade e das formas de apoderação dos saberes coletivos. A metodologia de apresentação debruça na exposição de quadros analíticos teórico-conceituais, depoimentos dos jovens e exposição de mapas coletivos feitos junto ao projeto Cartografia a ação e a juventude em São Gonçalo (2009-2011), em parceria com Ana Clara Torres Ribeiro.

As principais contribuições deste trabalho são duas: a primeira refere-se à atualização do debate da produção de mapas em um contexto de investimentos tecnológicos sofisticados em programas importados, onde a contraposição da cartografia da ação social, como a expressão do cotidiano vivido

1 Docente Associado da FFP/UERJ. Geografia, Programa de Pós Graduação em História Social, Programa de Pós-Graduação em Geografia da FFP/UERJ. 
e praticado, pode ser mapeada de forma sofisticada ou não. O mais importante é a produção coletiva do mapa a partir de uma problemática vivida e percebida pelo grupo social. A segunda contribuição refere-se ao debate do fazer científico diante da sociedade informacional, na qual o uso da internet permite rapidamente a divulgação da pesquisa. Nesse contexto, cria-se um questionamento: como e quando divulgar a cartografia da ação social dos grupos populares? Como fazer uma ciência geográfica pautada nos princípios éticos que orientam o cuidado com os saberes do outros? Esses são desafios que a ciência geográfica do século XXI precisa enfrentar.

Para identificar os agentes produtores do processo da degradação ambiental, foi apontado o reconhecimento do papel do Estado, os agentes econômicos e as formas de organização, reinvindicação, protestos e lutas sociais dos moradores e pescadores da região. Nesse processo pedagógico, utilizamos a proposta conceitual da cartografia da ação social. Esse conceito, proposto por Ana Clara Torres Ribeiro, norteou a metodologia de criação de mapas produzidos pelas crianças e adolescentes, reconhecendo as ações por meio de elaboração de símbolos: localização dos pescadores e dos problemas, identificação das áreas de protestos, localização do poder público e das barqueatas. $\mathrm{O}$ uso da Cartografia da Ação, principalmente em algumas atividades práticas, possibilitou promover um processo de aprendizagem mais autônomo e livre de discursos pré-estabelecidos e preexistentes nos textos didáticos.

Segundo Ribeiro et al. (2004), a cartografia da ação social é aquela passível de compreensão e de representação do movimento da sociedade, das lutas e de novos anseios, das açóes e desejos das bases populares. É a cartografia da ação que também representa o cotidiano da vida coletiva. Desse modo, a cartografia sugerida aqui é a da denúncia e também a que orienta a ação social, desvendando contextos e antecipando atos (Almeida, 1994). Significa, portanto, a contextualização veloz da ação hegemônica, cada vez mais estrategicamente localista, assim como a valorização imaginativa dos lugares vividos, onde a vida escorre ou ganha força reflexiva e transformadora. Como carta, o mapa não aparece como instrumento isolado ou como bela ilustração de textos, exacerbando critérios estéticos, mas sim como ferramenta analítica e sustento da memória dos outros. Neste sentido, propõe-se uma cartografia incompleta que se faz fazendo. Uma cartografia praticada que não seja apenas dos usos do espaço pelo poder, mas também utilizável, possibilitando a sincronia espaço-temporal, o que apoiaria, inclusive, o trabalho interdisciplinar (Ribeiro, 2012, 2013). Essa seria uma forma de representação da ação que poderia alimentar narrativas e que, em vez do território naturalizado, trataria de território usado, como orienta Milton Santos (1996, p. 18). O território não é uma categoria de análise, mas sim o território usado. Ou seja, para que o território se torne uma categoria de análise dentro das ciências sociais e com vistas à produção de projetos, isto é, com vistas à política, deve-se tomá-lo como território usado (Ribeiro et al., 2001-02, p. 4).

A cartografia da ação social é aquela não oficial, que trata das trajetórias das bases populares, das rotas de lutas e manifestações, trajetórias de trabalho no cotidiano, manifestaçôes culturais, ou das normas sociais ocultas não estatais. Com essa orientação, é possível desvendar um novo mundo, desvelar o invisível, ver beleza no anonimato, enxergar potencial no não considerado, naquilo e naquele visto como pobre de tudo. A proposta articula o pensamento de Milton Santos (1996) sobre os homens lentos, com o de Paulo Freire (1979) sobre a dimensão do compromisso humano, compromisso de reflexão e de consciência frente às contradições e as ambições que criam as fragmentaçōes e as segregações socioespaciais. Assim, a cartografia da ação social pode ser considerada, no contexto 


\section{A cartografia da ação social e a cidade de São Gonçalo, RJ}

de compreensão de um humanismo concreto, como uma categoria analítica e, ao mesmo tempo, metodológica. Isso porque ela permite experimentar por meio de exercícios de construção de novos mapeamentos e símbolos construídos a partir de um contexto do espaço vivido e concebido às novas formas de representação, aos novos projetos e aos novos sentidos das ações dos sujeitos vistos como comuns, banais. É preciso que estejamos abertos para ver novas possibilidades de redesenho do mundo, de escrita de nossa própria história, história das bases populares (Santos, 1996; Certeau, 1998).

O presente artigo tem a intenção de apresentar elementos centrais sobre a cartografia como técnica e processo no contexto da geografia. Busca-se expressar a experiência realizada com o projeto de investigação compartilhado com a professora Ana Clara Torres Ribeiro e seu grupo de pesquisa LASTRO/IPPUR, junto aos pesquisadores do nosso grupo de pesquisa Urbano, Território e mudanças contemporâneas - FFP/UERJ, que contribui muito para o diálogo entre a geografia e a sociologia no debate conceitual e metodológico e para o amadurecimento do sentido de fazer ciência na contemporaneidade (Silva, 2012).

O texto é dividido em duas partes. Uma seção é dedicada à compreensão do debate conceitual e a proposição metodológica da compreensão da cartografia como processo. A segunda seção busca expor algumas experiências realizadas no âmbito do projeto de pesquisa Cartografia da ação e a juventude em São Gonçalo.

\section{Cartografia da ação social e caminhos metodológicos: diálogos entre geografia e sociologia}

Cartografia da ação social é um conceito-instrumento metodológico criado por Ana Clara Torres Ribeiro, desenvolvido ao longo de 16 anos de elaboração do Banco de dados Processos Sociais. Com muitas referências de investigação, destaca-se, entre elas, o projeto "Cartografia da ação e análise de conjuntura: reivindicaçôes e protestos em contextos metropolitanos”, de 2001, e o seu diálogo de longos anos com a Geografia brasileira.

Durante o desenvolvimento desse projeto, a autora consolidou a metodologia que estrutura o banco de dados complexo sobre as formas de lutas e reivindicaçôes dos diferentes grupos sociais na luta pelo direito à cidade em contextos metropolitanos, denominando-o Banco de Processos Sociais. Esse banco, que é alimentado há 16 anos, permite identificar as trajetórias sociais, institucionais e espaciais dos sujeitos e dos movimentos sociais.

Desse modo, Ribeiro trouxe contribuições ao debate, hoje conhecido como o campo das cartografias sociais (Santos, 2011; Acselrad, 2010; Almeida 2009), que problematiza o uso da cartografia como uma das formas de representação social e de demonstração pública das formas de luta por território pelos sujeitos que vêm confrontado os grandes agentes.

No entanto, a diferença entre essas abordagens e a abordagem de Ribeiro refere-se não somente à atenção aos movimentos sociais, mas também aos "movimentos espontâneos" - isto é, as sociabilidades não institucionalizadas a priori, que se conformam nas lutas insurgentes construídas nos limites do suportável na convivência social, obedecendo a normas morais cotidianas do lugar, que vão muito 
além das normas do Estado. Ana Clara Torres Ribeiro conta que, certa vez, ao analisar seu banco de processos sociais, reconheceu a insurgência de um confronto público coletivo a um estuprador na metrópole de Belém. Ela o descreve não como um movimento organizado estrategicamente, mas um movimento espontâneo, demonstrando os limites do suportável coletivo.

Essa construção analítica permite ver as formas de apropriação urbana, a vida metropolitana como vida coletiva, a relação do agir com o sentido das ações, que relaciona razão e emoção, moralidade, espacialidade, sociabilidade, vínculo social e protestos, concretizando-a. Essa leitura, apoiada em Certeau (1998), trata do homem ordinário, ou seja, da construção da vida cotidiana, as trajetórias das práticas do cotidiano. Ela também expressa uma leitura das formas de representação que dá sentido e forma à relação entre sujeito e espaço vivido e espaço concebido. Assim, o diálogo entre a geografia e a sociologia, no entendimento de Ana Clara Torres Ribeiro e corroborado por nós, expõe a relação entre território e ação social na compreensão da relação espaço-tempo do cotidiano. Dos trajetos e arte de viver dos homens lentos (Santos, 1994), dos homens simples (Martins, 2000), dos homens ordinários (Certeau, 1998), os diálogos possíveis na compreensão de duas orientações.

A que vai trabalhar metodologicamente com os estágios de vivência, história oral e grupos focais, permite compreender o cotidiano vivido, o sistema simbólico, os elementos e sentidos que norteiam as ações. Essa possibilidade metodológica, como bem citam as referências de Ana Clara Torres Ribeiro e de Michel de Certeau, que aprofundam o entendimento às referências conceituais da relação entre o cotidiano e a experiência urbana, o que permite ver os interstícios das lutas, reivindicações e insurgências. Como outro lado da mesma moeda, compreendendo numa possibilidade dialética, há os modelos de resistências e de insurgências como enfretamentos às formas de racionalidades dominantes na modernidade. Essas formas concretizam as estruturas do poder e, por isso, da dominação política, econômica, social e cultural. É nesse contexto complexo e ontológico que o sentido do fazer científico se estabelece e é nele que se torna fundamental compreender a cartografia como técnica, como instrumento e como processo. É o que veremos a seguir.

\section{Cartografia como técnica social}

A produção ampliada da sociedade informacional está no centro da problemática da modernidade neste século XXI e teve origem em meados de do século XX (Ianni, 2000). Ribeiro (2012) nos ensina que na sociedade de consumo mediada pelas novas tecnologias de comunicação e informação está o entendimento de que o estudo da técnica é uma exigência da pesquisa, tanto de formas contemporâneas de dominação - apoiadas em ideários de eficácia e monitoramento do tecido social - quanto das resistências e afirmações sociais. Para os projetos dominantes em curso e o advento da globalização, a técnica, que inclui objetos e práticas codificadas, sustenta sistemas e sistematicidades, modelos e paradigmas. Por essa razão, inscreve-se nas formas de apropriação do espaço, criando rotinas ou rupturas planejadas do cotidiano e também gerando sistematicidades que podem impedir conquistas sociais ou se constituir no próprio ápice dessas conquistas (Ribeiro, 2012).

Com essa compreensão da técnica, a experiência urbana é apreendida como um embate contínuo entre sistematicidades efetivadas ou potenciais, movidas por diferentes formas de comunicação, 


\section{A cartografia da ação social e a cidade de São Gonçalo, RJ}

linguagens, táticas e recursos de poder (Ribeiro, 2012; Britto, 2010). É nesse contexto que estão inseridos os programas informacionais modernos de geoprocessamento e mapeamentos. Esses programas sofisticados reduzem o tempo da produção do mapa, mas também reduzem, na mesma velocidade, o domínio cognitivo sobre os processos de produção e confecção cartográficos, tornando os geógrafos consumidores quase perfeitos das tecnologias monopolizadas cada vez mais por grandes empresas. No Século XXI, a leitura cartográfica se torna cada vez mais usual e informacional, com as possibilidades fantásticas produzidas por empresas transnacionais.

Nesse sentido, a cartografia como técnica que agora se encontra em todos os lugares com recursos instantâneos e megaespaciais precisa, pelo menos no campo da geografia e do ensino dela, de uma reflexão epistemológica urgente. Ou seja, uma que remeta à filosofia da ciência, ao significado e sentido de seu uso. O reconhecimento crítico de suas possiblidades e de seus limites feito por Renato Emerson dos Santos (2011) analisa Alfredo Wagner Almeida e reconhece o contexto atual da "guerra de mapas" e das cartografagens como luta e resistência no combate pela visibilidade de suas manifestações e domínio de território, assim como a luta contra as cartografias “oficiais". Também autentica a necessidade dessa reflexão no momento em que seu uso contemporâneo entra em um processo acentuado de racionalização prática e construção de uma rotina do fazer científico, no sentido weberiano em que tudo pode ser mapeado (Weber, 2001). Desse modo, a ação do Estado e das empresas (inclusive com forte presença nos relatórios de impacto ambiental), a exposição de mapas, muitas vezes desenhado sobre o território e induzido a leituras de uma única verdade - tais como fazem parecer no debate sobre "a tradição da leitura dos vazios demográficos" no território brasileiro.

A cartografia como instrumento de representação espacial não pode ser considerada, como única finalidade, o mapa em si. A feitura de concretude da representação deve ser vista como processo de construção social. No capitalismo contemporâneo, onde a ciência torna-se objeto exposto ao consumo, as técnicas de representação como as leis impõem uma leitura de mundo predominante.

É fundamental perder a inocência da leitura cartografia sem uma crítica que inclua as geografias das existências - ou seja, que não deixe de saber que a totalidade do espaço é muito maior do que qualquer forma de representação espacial. O mapa é forma de representação, mas não da totalidade do espaço geográfico. Ele expressa mais a leitura do que a referência à totalidade das verdades.

Mas a verdade é composta de várias objetividades e subjetividades, portanto de muitas leituras e formas de representação, como bem expõe Lefebvre, que identifica o debate sobre a representação social e espacial e analisa a força político-social da construção das formas dominantes de representação. Badiou (1995) nos ajuda a refletir sobre a complexa construção social das verdades contrapondo às opiniōes. No entanto, o autor diz que a verdade como objetividade esconde os ascetismos - "o que é idêntico ao descobrimento do sujeito de verdade como puro desejo de si” (Badiou, 1995, p. 67). Há um sentido, muitas vezes não dito, que constrói um universo cultural de consentimentos que traz a tona alguns elementos e ações, e invisibiliza outros. O mapa como materialidade e representação contribui para esta visibilidade-ocultamento, de acordo com as intencionalidades do sujeito do conhecimento e produtor. 


\section{Cartografia como processo}

Compreender a cartografia como um processo social é uma busca metodológica complexa, mas é necessário aprender a fazê-la. Nesse processo, a confecção do mapa não é o centro nem o sentido das ações. Ele se inicia com as indagações dos sujeitos sociais e/ou institucionais - por que e para que fazer um mapa? Quais as intençôes e intencionalidade? Por que espacializar processos, coisas e açôes? Ao compreender os sentidos, deve-se problematizar o seu uso. Afinal, quem vai ter acesso? Por que e como divulgar? Para a racionalidade dominante - do Estado e das empresas -, espacializar é impor uma dada leitura de mundo como verdade e como norma a ser seguida e, portanto, institucionalizada. Têm-se os mapas políticos, rodoviários, de eventos, dos grandes projetos etc., que acabam por construir ou fortalecer os imaginários urbanos e as fronteiras sociais. $\mathrm{Na}$ maioria das vezes, esses mesmos mapas tornam ocultos processos sociais cotidianos.

O maior exemplo que conheço atualmente são os mapas das grandes empresas que representam os territórios costeiros, onde se destacam as cartas náuticas, que são atualizadas em uma velocidade anual, demarcando os novos empreendimentos, as zonas de contenção à pesca e a navegação. Contemplam áreas como a baía de Guanabara, onde se localizam 42 pontos de pesca artesanal e outros pontos de pesca amadora ou industrial que não aparecem no mapa.

A cartografia como processo é feita problematizando os ocultamentos de desenvolvimentos sociais e ambientais de seres, corpos e ações que se tornam invisibilizados. A contraposição consiste na cartografia da ação social, que busca compreender os conflitos no uso do território e as leituras e subjetividades (identidades, memórias, pertencimento) dos sujeitos em seu cotidiano, que muitas vezes têm visto seu dia a dia romper por causa de ações e próteses que são instaladas de repente. A cartografia da ação social reconstrói a outra leitura que força, no mundo do visível, a ruptura dos ocultamentos.

\section{Cartografia como processo: juventude em São Gonçalo}

De agosto de 2010 a dezembro de 2011, realizamos o projeto Cartografia da ação e a juventude em São Gonçalo, com a contribuição da coordenadora Ana Clara Torres Ribeiro (IPPUR/UFRJ) e de Ivy Shipper, seu bolsista, geógrafo mestre em Planejamento urbano e regional (IPPUR/UFRJ).

O projeto seguiu dois caminhos metodológicos:

1. Realização dos grupos focais com jovens de 17 a 29 anos estudantes ou trabalhadores moradores em São Gonçalo;

2. Crianças de 9 a 14 anos entre o $4^{\circ}$ e $5^{\circ}$ ano do ensino Fundamental no Colégio Carlos Maia, em Porto Velho, bairro de São Gonçalo. O trabalho contou com sete grupos focais de jovens trabalhadores e/ou estudantes, o último deles em agosto de 2012. As atividades nas escolas aconteceram com quatro turmas, com apoio das professoras regentes. 


\section{A cartografia da ação social e a cidade de São Gonçalo, RJ}

Nos dois caminhos metodológicos, partimos do confronto entre a percepção da cidade, das fronteiras invisíveis e dos imaginários urbanos, trabalhando com recorte de notícias sobre São Gonçalo e sua relação com o conhecimento vivido pelos sujeitos participantes das atividades. Ao longo das oficinas, os mapas impressos com seus contornos e ruas eram a base para a reflexão dos problemas e das possibilidades existentes na cidade de São Gonçalo, que experimenta a vida metropolitana.

Dentre os roteiros, orientava-se, sem fazer perguntas diretas aos entrevistados para deixar fluir o pensamento dos jovens. O grupo focal se organizava como uma roda de conversa, com um pesquisador fazendo o papel de estimulador de questóes. Outro pesquisador realizava o registro e outro observava os encaminhamentos. Dentre os grupos, uma entrevista foi realizada um com oito meninas residentes no bairro do Salgueiro, guiada pelo roteiro abaixo:

\section{Roteiro de grupo focal}

- Sobre o trabalho/estudo

- Desde quando estuda/trabalha?

- Onde essas atividades se localizam?

- Como você começou a trabalhar?

- $\quad \mathrm{O}$ que você pensa dessa atividade?

- $\quad \mathrm{O}$ que você aprendeu com essa atividade?

- Os jovens trabalhadores são diferentes dos mais velhos? Como?

- Você pretende continuar nesse trabalho?

- Como está nos estudos?

- Quais dificuldades?

- Quais possibilidades?

- Você pode descrever o seu trabalho/ estudo?

\section{(I) Apropriação do espaço urbano:}

- Onde você mora? É muito difícil chegar ao seu trabalho?

- Quais são os lugares que você mais frequenta em São Gonçalo?

- Quais são os lugares de São Gonçalo que você gostaria de conhecer?

- Porque você não os conhece ainda?

\section{(II) Segregação espacial (Percepção e experiência)}

- Quais são os melhores lugares de São Gonçalo para você? 
- E quais são os piores?

- Onde é o centro de São Gonçalo para você?

- O que você pensa sobre o Alcântara?

- O que o seu trabalho ensinou sobre São Gonçalo? E sobre o Alcântara?

(III) Identidades sociais e conflitos espaciais:

- Você se sente ligado a São Gonçalo?

- Você gostaria de trabalhar em outro lugar? Por quê?

- Como os seus amigos veem o seu trabalho? E a sua família?

- Como os lojistas veem o seu trabalho? E a polícia?

- Você já enfrentou dificuldades no seu trabalho? Quais? Quando?

- Quem ajudou você nesses momentos?

(IV) Sociabilidade: vínculos sociais, redes sociais:

- Quem são os seus melhores amigos?

- Qual é o melhor lugar para fazer amigos?

- O que é diversão para você?

- Como você se diverte?

(V) Desigualdades sociais (percepção e experiência)

- Você vê muitas diferenças sociais em São Gonçalo?

- Quais são essas diferenças?

- Os moradores de São Gonçalo lutam por seus direitos?

- Quem mais luta por seus direitos? Como?

- Quais são as principais necessidades da juventude de São Gonçalo?

- Quais são as necessidades dos jovens que trabalham como vendedores ambulantes?

(VI) Preconceito e exclusão social

- É difícil ser jovem? Por quê?

- Você acha que existe preconceito contra o seu trabalho?

- Você acha que preconceitos podem ser superados? Como? 


\section{A cartografia da ação social e a cidade de São Gonçalo, RJ}

\section{(VII) Imaginário urbano}

- Como são os jovens que você conhece?

- Você gostaria de conhecer outros tipos de jovens?

- Se você pudesse inventar um lugar para reunir os jovens de São Gonçalo, como seria?

- Aonde esse lugar seria?

- Você sente falta de acesso a atividades culturais? Quais?

- Você acha que o acesso a atividades culturais pode ser melhorado? Como?

Fonte: RIBEIRO, Relatório de pesquisa, 2008-12.

\section{Algumas considerações do grupo focal com as meninas do Salgueiro}

A partir da transcrição dos depoimentos apresentados nas rodas dos grupos focais, podemos tecer algumas considerações. Nosso objetivo, nesta seção, é apresentar os temas centrais do debate e que apareceram de forma muito frequente entre os presentes. Dispensamos a apresentação dos nomes das depoentes.

De modo geral, para elas, viver em São Gonçalo, no leste metropolitano fluminense, é relacionar-se ao todo com a região metropolitana do estado do Rio de Janeiro. É fazer parte do espaço social gonçalense convivendo com os limites e possibilidades de uma cidade metropolitana periférica que refletem nas relaçôes sociais e no modo de reconhecimento dos jovens pela cidade de São Gonçalo. A juventude do bairro Salgueiro proporciona uma análise dos desejos e anseios por uma cidade melhor na qualidade de vida, que refletem no modo que sociabilizam com outros indivíduos e com o espaço urbano gonçalense.

Esse panorama abre espaço para o questionamento individual: "o que é viver em São Gonçalo?”. Essa pergunta oferece reflexão que viver em São Gonçalo é fazer parte da história do espaço urbano. Cada jovem criou histórias que marcaram as vidas delas referentes à construção do espaço do município. Lembranças das amizades da época do colégio com conversas e brincadeiras na pracinha. Campeonatos de futebol no campinho do bairro como única atividade de lazer do local sem infraestrutura.

A juventude de São Gonçalo presume no urbano gonçalense a possibilidade de uma vida de qualidade. Para elas, é preciso haver serviços de assistência social no bairro do Salgueiro, por exemplo, assim como programas para prevenção da gravidez e de doenças sexualmente transmissíveis.

A busca por praias em outras cidades para lazer e diversão com amigos e familiares é um paradoxo. Em São Gonçalo, encontram-se as praias das Pedrinhas e da Luz. Mas por que os jovens se deslocam para outras cidades em busca de praias? O conhecimento do município de São Gonçalo pelas jovens gonçalenses é vago. A inviabilidade de deslocamento pela cidade é permanente, acarretando na 
falta de conhecimento de diversos lugares no espaço urbano do município. Dessa maneira, são criados conceitos pré-estabelecidos que determinados lugares não são prazerosos para lazer de uma juventude, que precisa dele para o desenvolvimento sociocultural.

São Gonçalo é a cidade dos encontros dos amigos em boates no Zé Garoto, Porto Velho, Porto da Pedra e Alcântara. Quando não há boates, os jovens se dirigem para Niterói e Rio de Janeiro. Em alguns bairros, não há casas noturnas, mas encontros nas ruas, que são fechadas para entretenimento.

Para a juventude do Salgueiro, em São Gonçalo, a educação oferecida a elas é péssima. Muitos buscam estudar em escolas em bairros distantes ou mesmo em outras cidades, uma vez que partem do princípio que as instituições de ensino de São Gonçalo não são de qualidade. Buscando uma educação melhor, deixam de construir relações com o espaço urbano gonçalense.

Na visão da juventude da cidade, trabalhar em São Gonçalo é algo impossível. Não há oferta de empregos suficiente para acolher essas pessoas que buscam um futuro melhor muitas vezes saindo de São Gonçalo. Embora o município tenha um milhão de habitantes, tem forte participação no PIB do RJ e apresenta forte diversificação dos postos de trabalho. Para os rapazes, sair de São Gonçalo em busca de emprego é fácil. Infelizmente, muitas moças afirmam que é difícil. As jovens mães gonçalenses analisam que não há creches públicas no Salgueiro. Pela falta de creches públicas municipais e estaduais, não há como as mulheres deixarem os seus filhos com pessoas seguras e capacitadas. Isso impossibilita as jovens mães de trabalharem, interrompendo a independência feminina no mercado de trabalho.

Sob a ótica dos entrevistados, a saúde é vista com descaso pelo poder público. Em um bairro como o Salgueiro, onde não há postos de saúde para consultas médicas, os moradores precisam se deslocar para os poucos bairros que têm postos de saúde, como Neves e Jardim Alcântara. A juventude que anseia por uma cidade melhor reivindica melhores condiçóes do sistema de saúde que a cidade tem.

São Gonçalo, cidade do prazer e do desprazer, onde as lembranças afetivas estão intrinsecamente ligadas aos momentos de felicidade. Ao mesmo tempo, cidade rejeitada pela juventude onde há falta de qualidade de vida. Essas duas faces de sentimento se encontram unidas como uma moeda.

São Gonçalo, cidade dos sonhos da juventude gonçalense para um futuro melhor. As jovens do Salgueiro sonham viver em uma cidade que possa proporcionar lazer e se sentirem confortáveis em um espaço urbano que proporcione felicidade e qualidade de vida. Esses sentimentos de carinho pela cidade são limitados pela falta de planejamento urbano social, que afeta todos os jovens que almejam viver um futuro melhor onde os vínculos familiares estão intrínsecos com o espaço urbano.

Viver em São Gonçalo é conviver com os sentimentos de saber que está próximo do convívio afetivo e também se limitar nas carências que todo indivíduo em um espaço urbano necessita. A juventude do bairro do Salgueiro sonha com uma cidade melhor para poderem viver com qualidade no espaço onde estão as memórias marcantes da formação sociocultural. Em síntese, foram estes imaginários sociais expressivos desse grupo de meninas que, de certa forma, apareceram também nos depoimentos dos outros grupos focais realizados com ambulantes, músicos e estudantes universitários da Faculdade de Formação de Professores da Universidade do estado do Rio de Janeiro (FFP-UERJ). 


\section{A cartografia da ação social e a cidade de São Gonçalo, RJ}

\section{Outra experiência do projeto: a cartografia das crianças}

Entre as atividades desenvolvidas no Colégio Carlos Maia no período de 2010 a 2011, apresentaremos resultados de uma oficina que aconteceu em sala de aula. O objetivo da atividade era compreender a leitura das crianças em relação aos problemas ambientais e dos pescadores existentes em São Gonçalo com seu entorno - a baía de Guanabara. O bairro da escola é banhado pelas águas da baía e, próximo a ela, está uma comunidade de pescadores chamada Esso, onde também há uma área de embarque e desembarque. A partir da leitura de notícias de recortes de jornais e de depoimento dos pescadores, foi elaborado um glossário (tipo de vocabulário para entendimento comum) e um quadro analítico que buscasse reconhecer: os agentes, as ações, as reivindicações, os opositores, os tipos de protestos ou manifestaçóes. Com essa base elaborada e discutida, os estudantes da turma do quinto ano elaboraram um mapa baseado nas fronteiras e nos principais bairros.

O resultado do trabalho que reconhece a cartografia da ação social como processo pode ser visto a seguir. O ponto de partida foi um conjunto de problematizações trazidas pelas notícias de jornais e pelo olhar das crianças. Na semana seguinte, os alunos trouxeram para a sala um pescador militante e realizaram entrevista com ele. No trabalho de análise, antes de trabalharem efetivamente no mapa, as crianças conseguiram identificar no espaço representado a localização das barqueatas (formas de manifestações dos pescadores para realizar algum tipo de protesto e reivindicação), as empresas indústria naval, petroquímica, localização dos resíduos sólidos e muitos outros agentes, usos e problemas existentes.

Figura 1. Aplicação da metodologia da cartografia da ação na escola.

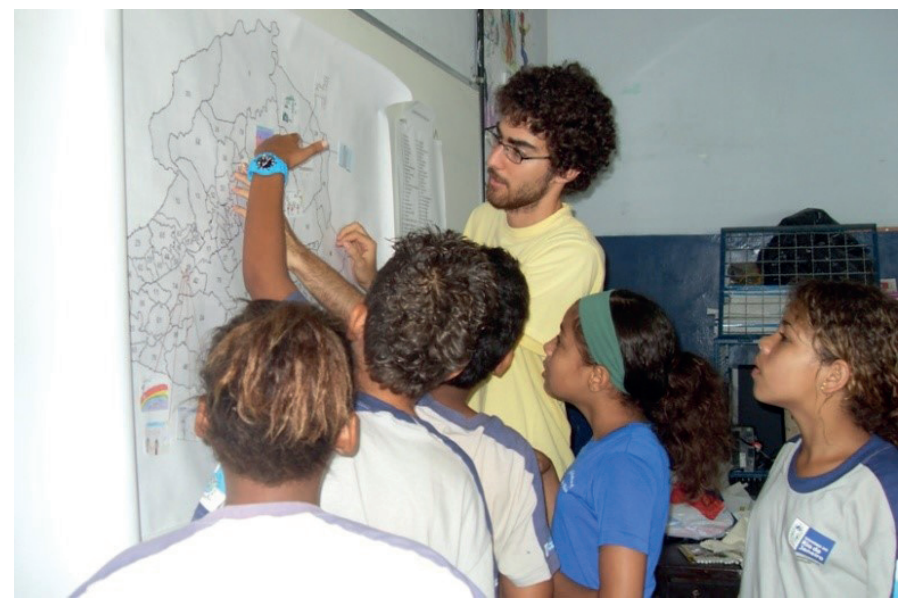

Fonte: Relatório Final. LASTRO-IPPUR-UFRJ\& NUTEMC-FFP-UERJ, 2011.

A produção coletiva do mapa utilizou, em sala de aula, vários recursos discursivos e didáticos, com formatos diversos e a ideia de troca de saberes proporcional a possibilidade de produzir um ensino de geografia fundamentada nas formas de representação da existência no sentido de Sartre - o ser não se constrói pela sua essência. É, antes de qualquer coisa, elaborada na sua reflexão no mundo, portanto no contexto social, cultural, político e espacial no qual se constrói de forma permanente. 
Trata-se da compreensão da pedagogia que se torna livre no exercício da consciência (da ação e sentido dessa ação) como bem ensina Freire (2008). É nesse contexto, confrontando outros mapas, que é possível compreender que o mapa é existencial, sempre um recorte, uma leitura de mundo. Não é a totalidade, mas o que a leitura quer demonstrar.

\section{Algumas conclusões para encaminhamentos do fazer geográfico}

Aproximando-se das conclusões, vale expressar algumas preocupaçōes que estamos atentos no fazer geográfico cotidiano. A primeira delas consiste no entendimento do que é produção da cartografia na contemporaneidade. Limites a serem ultrapassados pelo fazer cartográfico são fundamentais, tendo como referência epistemológica a questão cartografia: "pra quem?”, "cartografia para que?”. $\mathrm{Na}$ superação de limites, superar o fazer cartesiano - ciência das sínteses para a ciência da complexidade (Morin, 1996), em que o mapa deixe de ser o fim para ser o meio do fazer e do saber. Cartografar movimentos da sociedade, das apropriaçôes urbanas, territoriais e o que permite compreender a representação cartográfica como processo social (Ribeiro, Silva, Schipper, 2011). Novas metodologias, incluir sentidos do sujeito, tempo lento da troca de saberes, apreender o cotidiano dos grupos sociais. A cartografia como processo - do sentido, as ações, as problematizações, as formas de representaçōes (mapa, lei etc.) -, valorização da análise processual e não somente do objeto em si. Necessária reaproximação da ciência e arte (linguagens e símbolos) - expressão de movimentos, sentidos, lutas, protestos e reivindicaçôes, medos e desejos (Ribeiro, 2010).

A cartografia dos sujeitos é, na verdade, a cartografia da ação social deles, que incluem ações e intenções - quem elabora o tema e a simbolização, quem elabora os sentidos da ação social.

Estamos diante de uma alteração de paradigma científico necessária - sair das sínteses para a complexidade -, produção de teoria social e geográfica ao alterar a metodologia entender os sentidos, dialogar com o outro - o outro como sujeito por meio de novas maneiras de fazer a pesquisa de campo, o trabalho analítico e as formas de expressão do conhecimento.

\section{Referências}

ACSELRAD, Henri (org.). Cartografia social e dinâmica territorial: marcos para o debate. Rio de Janeiro: IPPUR-UFRJ, 2010.

ALMEIDA, Alfredo W. Nova cartografia social da Amazônia. Manaus: PPGSCA, 2009.

BADIOU, Alain. Ética: um ensaio sobre a consciência do mal. Rio de Janeiro: Relume Dumará, 1995.

BRITTO, Fabiana D. "Co-implicações entre corpo e cidade: da sala de aula à plataforma de açôes". In BRITTO, F. B. e JACQUES, P. B. Corpocidade: debates, açōes e articulaçôes. Salvador: UFBA, 2010, pp. 12-23. 
CERTEAU, Michel de. “A invenção do cotidiano”. Artes do fazer. 3 ed. Petrópolis: Vozes, 1998.

CORDEIRO, Denise. Juventude nas sombras. Rio de Janeiro: Lamparina \& FAPERJ, 2009.

FREIRE, Paulo. Pedagogia da esperança. São Paulo: Paz e Terra, 2008.

IANNI, Octavio. A sociedade global. Rio de Janeiro: Civilização Brasileira, 1992.

LEFEBVRE, Henri. O direito à cidade. São Paulo: Documentos, 1969.

. "La presence et l'absence". Contribution à la theorie das représentation. Paris: Casteman, 1980.

MARTINS, José de Souza. A sociabilidade do homem simples. São Paulo: Contexto, 2008.

MORIN, Edgar. Ciência com consciência. Rio de Janeiro: Bertrand Brasil, 1996.

RIBEIRO, Ana Clara T. "Pequena reflexão sobre categorias da teoria crítica do espaço: território usado, território praticado". In SOUZA, Maria Adélia Aparecida de (org.). Território brasileiro: usos e abusos. São Paulo: Edições Territorial, 2003.

Relatório técnico-científico do projeto: territórios da juventude: experiências em cartografia da ação (São Gonçalo, RJ). Edital Humanidades. Rio de Janeiro: FAPERJ, 2008-12.

. "Dança de sentidos: na busca de alguns gestos". In BRITTO, F. B. e JACQUES, P. B. Corpocidade: debates, ações e articulações. Salvador: UFBA, 2010, pp. 24-40.

. Por uma sociologia do presente: ação, técnica e espaço. Rio de Janeiro: Letra Capital, 2012, v. 1.

. Por uma sociologia do presente: ação, técnica e espaço. Rio de Janeiro: Letra Capital, 2013, v. 5 .

e SILVA, Catia Antonia da. "Faces ativas do urbano: mutaçôes num contexto de imobilismos”. In (org.). Repensando a experiência urbana da América Latina: questões, conceitos e valores. Buenos Aires: CLACSO, 2000, pp. 96-125.

et al. "Por uma cartografia da ação: pequeno ensaio de método". Cadernos IPPUR, ano XV, n. 2 e ano XVI, n. 1, 2001-02.

et al. Relatório técnico-científico do projeto: cartografia da ação e análise de conjuntura: reivindicações e protestos em contextos metropolitanos (quatro volumes). Programa Cientista do Nosso Estado. Rio de Janeiro: FAPERJ, 2005-06.

et al. "Cartografia da ação e a juventude na cidade: trajetórias de método". In et al. (orgs.). Cartografia da ação e movimentos da sociedade: desafios de método e experiências urbanas. Rio de Janeiro: Lamparina, 2011, pp. 31-42.

SANTOS, Boaventura de Souza. "Uma cartografia simbólica das representações sociais: prolegômenos a uma concepção pós-moderna do direito”. Espaço \& Debates, v. 33, ano XI, 1991.

SANTOS, Milton. Técnica, espaço, tempo: globalização e meio técnico-científico informacional, São Paulo: HUCITEC, 1994.

. A natureza do espaço: técnica e tempo, razão e emoção. São Paulo: HUCITEC, 1996.

et al. O papel ativo da Geografia: manifesto. XII Encontro Nacional de Geógrafos, Florianópolis, jul. 2000. 
SANTOS, Renato E. "Cartografias e lutas sociais: notas sobre uma relação que se fortalece. In RIBEIRO, Ana Clara Torres et al. (orgs.). Cartografia da ação e movimentos da sociedade: desafios de método e experiências urbanas. Rio de janeiro: Lamparina, 2011, pp. 43-60.

SILVA, Catia A. da. "O fazer geográfico em busca de sentidos ou a geografia em diálogo com a sociologia do tempo presente”. Boletim Campineiro de Geografia, v.2, p.1, 20-21, 2012.

e SCHIPPER, Ivy. "Cartografia da ação social: reflexão e criatividade no contato da escola com a cidade”. Revista Tamoios [on line], v. 8, p. 20, 2012.

SOUZA, José G. e KATUTA, Ângela M. Geografia e conhecimentos cartográficos. São Paulo: UNESP, 2001.

WEBER, Max. Ciência e política: duas vocações. São Paulo: Martin Claret, 2001. 
Formato 16 × 23

Tipologia: Garamond (texto) Garamond (títulos) Suporte: PDF 